\title{
Turismo e medo do crime: reflexões sobre a política de desenvolvimento urbano no centro histórico de Natal/RN
}

\section{Tourism and fear of crime: reflection on urban development policy in the historical center of Natal/RN}

Ana Catarina Alves Coutinho - Doutoranda em Turismo e Desenvolvimento Regional, pelo Programa de Pós-Graduação em Turismo da Universidade Federal do Rio Grande do Norte (PPGTUR/UFRN). Membro do Grupo de Pesquisa em Planejamento e Organização do Turismo - GEPPOT/UFRN. Professora da Universidade Federal do Maranhão (UFMA). E-mail: coutinho.catarina1@gmail.com

Wilker Ricardo de Mendonça Nóbrega - Doutor em Ciências Socioambientais, pelo Núcleo de Altos Estudos Amazônicos da Universidade Federal do Pará (NAEA/UFPA). Líder do Grupo de Pesquisa em Planejamento e Organização do Turismo - GEPPOT/UFRN Professor e Pesquisador do Departamento de Turismo da Universidade Federal do Rio Grande do Norte (UFRN). E-mail: wilkernobrega@yahoo.com.br

Mozart Fazito - Doutor em Geografia, Planejamento e Política Ambiental pela Universidade Nacional da Irlanda (University College Dublin). Membro do Grupo de Pesquisa em Planejamento e Organização do Turismo - GEPPOT/UFRN. Professor do Departamento de Turismo da Universidade Federal do Rio Grande do Norte (UFRN). E-mail: mozart.fazito@gmail.com

\section{Resumo}

O presente artigo analisa o medo do crime e as suas relações com o turismo a partir da discussão do Estado neoliberal e a instrumentalização de ações de intervenção pública. Explora o centro histórico de Natal, que vem sendo alvo de intervenções de planejamento e desenvolvimento urbano ao longo dos anos. Emprega uma abordagem qualitativa de coleta e análise de dados documentais junto às secretarias envolvidas com o planejamento urbano, além de análises estatísticas criminais acerca do centro histórico de Natal. Assim, identificou-se quatro principais momentos da política de intervenção urbana onde o medo do crime foi construído e compartilhado a partir da ideologia de ordenamento e controle social. De forma específica, o turismo aparece como racionalidade a partir do terceiro momento com direcionamentos da reabilitação do centro histórico para justificar as ações e intervenções urbanísticas públicas direcionadas para o seu consumo.

\section{Palavra-chave}

Medo do crime. Desenvolvimento urbano. Turismo. Centro histórico de Natal/RN.

\begin{abstract}
This article explores the fear of crime and its relations with tourism based on a discussion of the neoliberal state and the manipulation of public intervention. It explores the historical center of Natal that has been the target of urban development and planning interventions over the years. It employs a qualitative approach for collection and analysis of documentary data from the departments involved with urban planning, in addition to criminal statistical analysis in the historical center. Thus, we identified four referential moments in urban intervention policies, where the fear of crime was constructed and shared from the ideology of social order and surveillance. Specifically, tourism appears as a rationality from the third moment onwards to legitimate the rehabilitation of the historical center, which aims to justify public urban actions and interventions directed at its consumption.
\end{abstract}

\section{Keywords}

Fear of crime. Urban development. Tourism. Historical center of $\mathrm{Natal} / \mathrm{RN}$. 


\section{INTRODUÇÃO AO MUNDO DO CRIME E A INTERFACE COM O TURISMO}

O processo de desenvolvimento da sociedade pós-industrial é marcado pela fluidez e avanços técnico-científicos em nome da modernização (FAZITO, 2015; HARVEY, 2014). Tudo aquilo que é visto como antigo e atrasado tornase objeto de restauração para a sua modernização, gerando desigualdades no processo de desenvolvimento urbano. As cidades, por sua vez, são reestruturadas visando o negócio através do progresso material que determina a riqueza e renda como variáveis determinantes para o seu sucesso (SOUZA, 2002).

Neste processo, junto com as novas conquistas trabalhistas, torna-se acessível o lazer e o turismo à classe trabalhadora, criando espaços públicos de sociabilidade e lazer visando o seu consumo (BAHIA; FIGUEIREDO, 2017). Os indivíduos se tornam meros consumidores como resultado da emergência da onda neoliberal que promove a diminuição do Estado e a desregulação do mercado, tornando as relações cada vez mais corporativas e competitivas. Assim, o lazer e o turismo são vistos como instrumentos para manutenção dessas relações e são empregados como vetores da modernização.

A partir da década de 1970, as capitais do Nordeste brasileiro receberam investimentos oriundos de políticas públicas para a expansão e manutenção de equipamentos turísticos (LIMA; COSTA, 2015), que geraram processos de reconfiguração urbana. Ideias utilitaristas, como a melhoria da qualidade de vida, fomentam e justificam as políticas de turismo nas localidades, mas geram conflitos com os residentes, com a estruturação de desigualdades sociais, exploração sexual, consumo de drogas ilícitas, aculturação, crimes ambientais, apenas para explicitar alguns exemplos. Estudos comprovam que essa reconfiguração urbana também provocou conflitos como o crescimento de segundas residências, o que impulsionou a chegada de um grande número de estrangeiros modificando o planejamento e realidades por meio de um olhar e uso quase que exclusivamente exógeno (FONSECA, 2012; URRY, 2002). A voracidade do consumo dos espaços, característica da modernização, é propiciada por contrastes, como entre pobre e rico, centro e periferia, avançado e atrasado, novo e velho, gerando uma onda de medo de frequentar espaços de alta polarização social (BAUMAN, 2009).

Apesar de sua relevância, a questão do medo social e da criminalidade urbana em cidades turísticas tem sido pouco explorada na literatura e está, majoritariamente, direcionada à percepção do turista, o que reforça valores modernizantes e neoliberais, como estratégia para definir as ações de planejamento do turismo local. 
Pesquisas no cerne da temática, como a de Mansfeld e Pizam (2006) e Korstanje (2017), sinalizam que o turismo não contribui para o aumento ou a diminuição da criminalidade nas localidades, por isso a busca por uma relação causal deve ser abandonada. Além disso, quando sentem vulneráveis ao risco e sentem medo, em muitos casos, não afetam a escolha ou indicação do destino, podem apenas postergar sua viagem. Estas constatações vêm sendo endossadas por pesquisas posteriormente realizadas. Na Eurásia, as pesquisas de Ozascilar, Mawby e Ziyalar (2019) constataram que os turistas possuem baixa percepção dos riscos e adquirem menos intenção de adotar alguma estratégia de precaução. Já o estudo de George (2010), na África do Sul, identificou que as atitudes em relação aos riscos percebidos pelos turistas não influenciam a intenção de retornar e recomendar o destino.

O cenário brasileiro segue a mesma tendência. Por exemplo, os estudos de Marcello Machado $(2013,2018)$ apontam que as altas taxas de criminalidade do Rio de Janeiro não representam critério restritivo de escolha para os turistas reais e potenciais. Já no Nordeste brasileiro, pesquisas apontam que as áreas que apresentam altas taxas de violência homicida não coincidem com as áreas de interesse turístico (COSTA et al., 2018; COSTA; HERRERA, 2019). O que estes estudos sinalizam é o reforço de um ideal do exógeno, forte ênfase nos impactos e não necessariamente na origem do medo, além de não apresentarem relação significativa entre medo do crime e interesse de visitação na destinação (ver demais estudos: ADAM; ADONGO, 2016; CHAUHAN, 2015; GIUSTI; RAYA, 2019; ROO; CORTÉS, 2016).

Entende-se que o medo dificulta a coesão social, fomenta o individualismo, fragmenta a experiência urbana e segrega os problemas urbanos (HALE, 1996), fazendo com que se criem setores de riscos, distanciando a ideia de uma cidade civilizada e de fluxo para todos, inclusive, turístico. A relação problemática entre medo e turismo nas cidades têm origem na modernização autoritária que vivenciaram as cidades brasileiras. As reflexões aqui postas contribuem para a formulação de políticas para um turismo humanizado e sustentável, a partir do entendimento do papel do turismo e do lazer no desenvolvimento urbano, que estimule processos libertários de consciência coletiva e ação social (SEN, 2000). Assim, este artigo $^{1}$ tem como objetivo analisar o medo do crime, a partir dos processos de intervenção urbana realizados no centro histórico de Natal/RN, no nordeste brasileiro. Essa análise percorre uma leitura temporal, utilizando a dialogia com os processos urbanos desencadeados.

O presente trabalho foi realizado com apoio da Coordenação de Aperfeiçoamento de Pessoal de Nível Superior -CAPES (Print) e da Academia Britânica (Newton Advanced Fellowships), e realizado no âmbito do Grupo de Pesquisa em Planejamento e Organização do Turismo (GEPPOT) e da Rede de Pesquisa OBVIO - Observatório da Violência. 


\section{DESENHO METODOLÓGICO PARA OS CAMINHOS DO CRIME URBANO}

Esta pesquisa parte do pressuposto de uma realidade que é socialmente construída, a partir dos desafios do mundo contemporâneo e das relações que foram estabelecidas ao longo dele com as estruturas sociais, as regras, os mecanismos, as normas e os poderes como fonte de evidência científica. Para tanto, recorre à necessidade de uma postura abrangente, histórica e complexa com ênfase em uma abordagem qualitativa da narrativa dos fatos, onde até os dados quantitativos também servem de subsídios para compreensão da realidade que é dialógica e complexa (RICHARDSON, 1999).

Como fonte de embasamento teórico, a investigação bibliográfica investigou as seguintes temáticas: medo do crime e políticas públicas urbanas com ênfase nas relações entre turismo e lazer. Fez-se uso do procedimento metodológico de Enslin et al. (2010), pesquisado nos idiomas em português, inglês e espanhol no recorte temporal de 20 anos. Todavia, após diálogo com especialistas na área, novas leituras foram sugeridas e incorporadas, que não estavam nesse recorte inicial, mas que foram consideradas relevantes. Este procedimento possibilitou a construção do portfólio bibliográfico com a definição de algumas categorias de análise que serão discutidas no tópico seguinte.

O recorte espacial desta pesquisa é centro histórico de Natal, que se justifica pela sua inserção e representatividade no campo cultural e turístico da cidade, além da presença de importantes atrativos turísticos históricos, notadamente identificados nos bairros de Cidade Alta e Ribeira. Essa área vem sendo objeto de intervenções públicas urbanísticas nos últimos anos, com interesses imobiliários privados (SILVA; SOBRINHA; CLEMENTINO, 2006).

A fim de analisar as políticas urbanísticas no centro histórico de Natal/ $\mathrm{RN}$, foram coletados dados por meio de pesquisa documental disponibilizados pela Prefeitura Municipal. Trata-se de análises e informações das Secretarias Municipais de Planejamento Urbano, da Secretaria Municipal de Serviços Urbanos, relatórios de pesquisas, além de documentos do Governo Federal que têm interface com a área de pesquisa desde a década de 1990. Especificamente, os documentos legislativos da área (Zona Especial Portuária, Zona Especial de Preservação Histórica, Planos diretores, entre outros) e programas de intervenção pública (PAC Cidades históricas, Programa ReHabitar, PRAC-Ribeira, Programa Monumenta, Circuito histórico da Semurb). Ademais, visando compreender o cenário da criminalidade urbana, utilizou-se de fonte estatística sobre as condutas criminais na cidade do Natal a partir do Metabanco do Observatório da Violência 
do Rio Grande do Norte (OBVIO/RN) enfatizando os Crimes Violentos Letais Intencionais (CVLI) e Crimes Violentos ao Patrimônio (CVP) investigados no período de 2011 a 2019.

A análise sociodemográfica usou como fonte o Instituto Brasileiro de Geografia e Estatística (IBGE) e documentos institucionais das secretarias, denominados "Conheça seu Bairro". Foi desenvolvida uma linha de tempo e foram feitos registros frutos de observação local. Tornou-se, assim, possível identificar as políticas públicas de intervenção urbana no centro histórico de Natal e a sua relação com o medo do crime.

\section{POLÍTICAS DE INTERVENÇÃO URBANA E O MEDO DO CRIME}

A obra Le droit à la ville (LEFEBVRE, 1969) apresentou uma série de pesquisas e questionamentos sobre as políticas urbanas, que foram incorporadas por planejadores urbanos, arquitetos, geógrafos, em todo o globo (CASTELLS, 1999; HARVEY, 1980; CARLOS, 1994). O que este e outros autores passaram a discutir não remete a uma denominação única e estática das políticas urbanas, mas um conjunto de demandas alicerçadas - principalmente quando se trata do contexto brasileiro - em uma tríade entre democracia, cidadania e autonomia como elementos constitutivos da formação de uma consciência coletiva.

Isso significa afirmar o entendimento de uma cidade autêntica dotada de contradições - conforme é seu processo constitutivo - mas que possa ser usufruída por todos com garantias de espaços públicos de lazer, mobilidade e habitação dignos, o que gera um quadro de melhor qualidade de vida a seus cidadãos. Todavia, as cidades foram inicialmente projetadas com pretensões urbanísticas baseadas em discurso técnico, muito mais do que científico, de modo que, financiadas pelo capital burguês, as estratégias eram de ampliação e embelezamento da cidade. As melhorias urbanas não se preocupavam com as questões higiênicas, sanitaristas, políticas e econômicas, o que veio acontecer posteriormente com o advento dos planos diretores - pelo menos em seu plano discursivo (VILLAÇA, 2005).

O que parece evidente nesse processo constituinte até a contemporaneidade é que as cidades se tornaram mercadorias, suscetíveis aos desejos do capital financeiro, onde se verifica um conjunto de estratégias que visam o melhoramento da aparência física voltado à produção e consumo (HARVEY, 2014). Deste modo, o consumo passa a ser fomentado por meio de intervenções urbanísticas, onde o medo se torna um dos objetos em um processo de retroalimentação por novas políticas urbanas. 
Alguns autores definem o medo como uma emoção, provocada pela consciência do perigo de uma ameaça (FARRALL; GRAY; JACKSON, 2007; JACKSON; GOUSETI, 2013; SILVA; BEATO FILHO, 2014).É individualmente experimentado, socialmente construído e culturalmente compartido. Neste processo, os pesquisadores têm identificado que intervenções urbanísticas ora contribuem para o aumento, ora para a diminuição do medo.

Sobre o primeiro aspecto (aumento do medo), a questão reside na organização social. A teoria da arquitetura do medo vem demonstrando que a forma como a cidade está disposta, por meio de enclaves fortificados, contribui para a segregação social, de modo que quanto mais muros, maior o distanciamento e desconhecimento do outro, como consequência, maior medo de frequentar o espaço (CALDEIRA, 1997; JACOBS, 1961). Parte-se do pressuposto de que o nível de proximidade física e de reconhecimento entre as pessoas do bairro aumentam o senso de pertencimento, coesão social e diminuição da sensação de medo.

As pesquisas de Fennel (2017) e Prechathamwong e Rujiprak (2018) identificaram, por exemplo, que a disposição das fachadas, transparência e espaços de transição, complexidade visual e de cores, a possibilidade de sentarse e garantir o convívio com o outro, determina a percepção do espaço físico. Esta dimensão espacial do medo do crime também se revela por meio de lugares abertos, fechados, grandes, pequenos e carregados de uma história, isto é, da forma de se relacionar com o espaço e as pessoas.

Para Sakip, Bahaluddin e Hassan (2016), embora o espaço seja pequeno, como é o caso de becos e ruelas, resultados de padrões arquitetônicos ibéricos, a arte exposta em murais públicos funcionou como uma estratégia para prevenir o crime na área e seu medo. Para De Biasi (2017), o medo do crime está relacionado a espaços desordenados e vazios, propondo um estudo sobre o design urbano verde para sua diminuição.

Autores também identificaram que edifícios abandonados, pichações, arborização mal cuidada, lixo e ruídos sonoros são considerados retratos de mau uso, revelam desconfiança em relação à segurança do espaço e geram medo e desuso (CÁRDENAS O’BYRNE, 2017; TRINDADE; DURANTE, 2019; JONES; BLAUSTEIN; NEWBURN, 2019).

As alterações em certas características físicas dos ambientes urbanos podem impedir os atos criminosos (o fato de se tornar vítima) ou em potencial (o medo). Uma cidade deve possibilitar olhar o outro, ser pensada para o convívio social e a civilidade. A qualidade de uma cidade, portanto, depende dos espaços públicos abertos que possibilite a interação, encontro, socialização e intercâmbio, inclusive para uso turístico. 
Por muito tempo, os planejadores urbanos perpetuaram a ideia de criação de espaços de única utilização, o que provocou a criação de eixos puramente comerciais, outros residenciais, expulsando para eixos marginais aqueles que não se enquadravam nestes elementos. Contemporaneamente, há uma perspectiva de regulamentação que considera o planejamento das cidades mais "leve", embora ainda prejudiciais sobre as ideias de uso misto e zoneamento inclusivo, com prerrogativas de controle urbanístico e discursos de inclusão política sem a efetiva participação (SOUZA, 2002).

É importante ainda considerar que quando o pensamento urbanístico tem que lidar com as práticas sociais no seu processo de planejamento, conforme apontava Lefebvre (1969), se depara com situações que tem no seu cerne questões complexas, contraditórias e que se renovam historicamente. Deste modo, observa uma patologia e sente a necessidade de controlá-las, higienizá-las e reorganizá-las de acordo com a racionalidade que opera.

Emerge, assim, o segundo aspecto discutido na literatura: a diminuição do medo por meio de um controle social. Essa abordagem aponta para uma roupagem física com estratégias de repressão a determinadas condutas e policiamento. Combate-se o vandalismo, comportamento desrespeitoso, embriaguez pública, problemas com drogas, entre outros (KARAGIANNIS; MADJD-SADJADI, 2012; OH; REN; HE, 2019; PRECHATHAMWONG; RUJIPRAK, 2018). Uma atuação que está no seio da história brasileira processos de repressão, encarceramento, segregação e vulnerabilidade social, gerando contradições no espaço (CERQUEIRA, 2014). Estudos apontam que a presença policial aumenta o medo do crime e gera uma sociabilidade violenta (BAIERL, 2008; SILVA, 2004).

Para Botterill et al. (2013), há um sistema de atuação policial sob o auspício de dois elementos que eles denominam como aquiescia da transgressão e conluio da negação ${ }^{2}$ que reforçam a ideologia da necessidade da atuação policial contra os crimes. Todavia, o que se verifica na prática é a consciência de um comportamento agressivo por meio da negação da sua existência, criando um sistema que reforça a violência. Assim, o medo gera uma capacidade simbólica de exercício informal de controle social, constituída pelo elemento físico, mas também de divisão social, afastando as áreas pobres por meio da estigmatização social.

2 Para o autor a aquiescia da transgressão é quando o indivíduo cede às tensões existentes para evitar incidentes de agressão. Como consequência, os guardiões (lê-se policiais), concordam com essa natureza criminológica dentro do espaço turístico. Como as tensões são resultados de um problema disfuncional e difíceis de resolver, provoca-se o Conluio da negação que significa acordar que ela não existe, apesar de reconhecer a gravidade da situação, o que permite a sua perpetuação. 
Fato é que há uma alteração da conjuntura social a partir de políticas que segregam territorialmente este espaço. De acordo com a investigação de Jackson e Gouseti (2013), os indivíduos que sentem o medo, tomam alguma iniciativa para sua mudança. Assim, para enfrentar o medo, a sociedade passou se isolar cada vez mais dentro de suas casas e seus problemas familiares, aprisionando-se em suas próprias vidas. Assim, um conjunto de empreendimentos imobiliários verticais foi incentivado na política urbana brasileira, com forte participação de instituições bancárias, contrapondo-se às teorias sobre a arquitetura do medo e os "olhos da cidade" (CALDEIRA, 1997, 2003; JACOBS, 1961). Assim, o medo se industrializa, criando assim, empresas especializadas na sua diminuição e/ou geração deste medo. Busca-se o fomento econômico a partir da ideologia de um controle social. Considerando o contexto do estado neoliberal, cada vez mais empresas passam a interessar por esta economia menos regulada pelo estado e mais autônoma para o mercado. Emerge o paradoxo de que o medo no contexto neoliberal é algo a ser comercializado e fomentado a partir da ideologia do seu combate.

Na esfera pública, uma série de medidas é tomada para essa reestruturação. As preocupações de infraestrutura urbana estão relacionadas ao pensamento pós-industrial, que direciona, inclusive, o olhar do turista a uma determinada percepção dos lugares visitados, gerando uma "globalização do olhar". Criam-se vias específicas para sua circulação revitalizando espaços urbanos em nome de uma ordem e de um controle social.

A partir da literatura aqui discutida foi possível identificar um portfólio bibliográfico (Quadro 1) com a definição de duas dimensões e algumas categorias sobre o medo do crime. Este portfólio servirá de base para a discussão dos resultados que serão apresentados nas próximas seções, em conjunto com a leitura das principais políticas de intervenção urbana no centro histórico da cidade de Natal, estado do Rio Grande do Norte.

Quadro 1 - Portfólio bibliográfico sobre o medo do crime

\begin{tabular}{|c|c|c|}
\hline Dimensão & Categorias & Autores \\
\hline $\begin{array}{c}\text { Organização } \\
\text { social }\end{array}$ & $\begin{array}{l}\text { - Possibilidade de sentar-se e } \\
\text { garantir o convívio com o outro } \\
\text { - Transparência e espaços de } \\
\text { transição versus construção de } \\
\text { enclaves fortificados } \\
\text { - Espaços desordenados e vazios } \\
\text { (abandonados) } \\
\text { - Disposição das fachadas e cores } \\
\text { - Pichações, lixo, arborização e } \\
\text { ruídos sonoros (música alta, barulho } \\
\text { de tiro, gritaria etc.) }\end{array}$ & 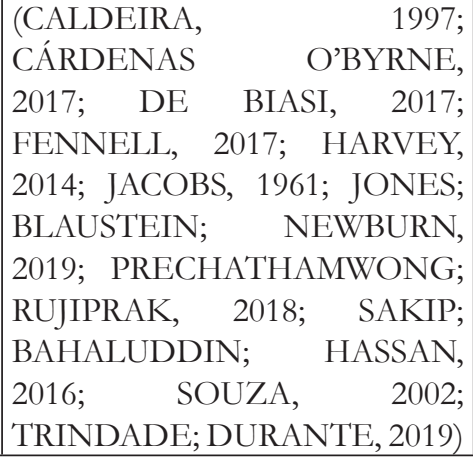 \\
\hline
\end{tabular}


(conclusão)

\begin{tabular}{|c|c|c|}
\hline $\begin{array}{c}\text { Controle } \\
\text { social }\end{array}$ & $\begin{array}{l}\text { - Comportamentos desordenados } \\
\text { (embriaguez, drogas, sexo etc.) } \\
\text { - Repressão e penalização policial } \\
\text { - Segregação e vulnerabilidade } \\
\text { social }\end{array}$ & $\begin{array}{l}\text { BAIERL, 2008; BOTTERILL } \\
\text { et al., 2013; KARAGIANNIS; } \\
\text { MADJD-SADJADI, } \\
\text { OH; REN; HE, } 2012 ; \\
\text { P R E C H A T H A M W O N G; } \\
\text { RUJIPRAK, 2018) } \\
\end{array}$ \\
\hline
\end{tabular}

Fonte: Organizado pelos autores com base nos dados da pesquisa, 2020.

\section{CENTRO HISTÓRICO DE NATAL: POLÍTICAS DE DESENVOLVIMENTO URBANO E MEDO DO CRIME}

O processo de desenvolvimento das cidades possui conexão com o seu crescimento urbano e as ideologias de desenvolvimento predominante. Assim, desde a fundação da cidade do Natal, o processo de sua ocupação define tipologias urbanas peculiares que possuem conexão com a forma que o medo do crime é socialmente construído e compartilhado.

Uma das primeiras características históricas ocorre no final do século XIX e início do século XX, marcado por regimes republicanos e o fortalecimento das oligarquias nas províncias que estabelecem um conjunto de reformas urbanísticas visando a modernização das capitais, quando surge o Plano Polidreli e Plano Palumbo. Naquele momento histórico Natal detinha os bairros da Cidade Alta - que, conforme nome revela, se situa em um ponto mais alto e estratégico de vista para o rio e o mar - e o bairro da Ribeira, que resguardava características para a vocação comercial, onde se armazenavam e exportavam importantes mercadorias (CASCUDO, 2010).

Estes planos redesenham o modelo da antiga vila, com características ainda coloniais visando obras de intervenção, correção, prolongamento e novos quarteirões. Como consequência da expansão, provocaram desocupações de habitações, emergindo o fenômeno da favelização que migra para o surgimento de novas áreas de ocupação como a Praia do Meio, Passo da Pátria às margens do Rio Potengi e posteriormente a comunidade do Jacó, no interior do bairro das Rocas (TINOCO; BEZERRA; TRIGUEIRO, 2007).

Assentadas nas aspirações de progresso voltado à constituição da república, as ações modernizantes eram justificadas e patrocinadas pela elite local com a finalidade de ampliação e embelezamento da cidade, regulamentando as construções, criando zoneamento e arruamento das cidades. Divide-se o território entre centro-periferia, trabalho e moradia, ricos e pobres através da criação de zonas específicas de consumo e moradia. Esta divisão organizacional da cidade pressupõe a lógica única de uso do consumo. Assim, alguns espaços 
são estruturados de forma ampla e aberta que permitem a circulação de pessoas (espaço de consumo) e outros são negligenciados a partir do processo de segregação social (espaço do medo). O medo é subjetivo, e é construído a partir de um conjunto de emoções que se partilha socialmente (FARRALL; GRAY; JACKSON, 2007; JACKSON; GOUSETI, 2013). Nesse processo, o medo passa a estar assentado nessas diferenças socioeconômicas, portanto é estigmatizado e cria vias e enclaves sociais que o alimentam.

Neste percurso histórico, é importante considerar que a cidade do Natal foi uma das sedes da II Guerra Mundial, com sua base de apoio situada em Parnamirim (município limítrofe no setor sul), acentuando o crescimento populacional e expansão da cidade para novos eixos. Essa expansão contribuiu para o segundo momento da política de intervenção urbana que tem seu marco no final dos anos 1970. Suas aspirações são imobiliárias, com a defesa de um processo de verticalização voltado para áreas litorâneas, mas não restrito a elas, onde o turismo aparece como um importante indutor. Vivia-se um momento de ruptura com a ditadura militar e posteriormente a abertura para o mercado globalizado. Sua intenção foi o fortalecimento desta economia que inicia com o processo de consolidação do Programa de Desenvolvimento do Turismo na década de 1990 (FONSECA, 2012).

Esse modelo brasileiro de urbanização fez com que os centros históricos entrassem em decadência, se constituindo como uma ameaça pela alteração da configuração urbana e paisagística. Além disso, gerou zonas periféricas que se revelam pelos usos e rapidamente desusos com ritmos sociais violentos (MELO, 2015). Essa decadência, em Natal, veio se acentuar nos anos 1960 e 1970, com a diminuição do movimento portuário, declínio das atividades comerciais e criação de novas estruturas como é o caso do Terminal Rodoviário em um novo bairro da cidade.

No âmbito nacional, foi instituído o Programa Cidades Históricas, em 1973, com a valorização socioeconômica que foi considerada uma das funções primordiais do patrimônio histórico. O objetivo principal do programa era preservar os monumentos históricos de forma a torná-los economicamente viáveis e, de fato, foi o primeiro programa que investiu em ações de recuperação dos patrimônios. Isto foi possível uma vez que as estratégias de preservação passam a incorporar uma dimensão urbanística.

Essa onda preservacionista na defesa de salvaguardar o patrimônio, passa a estar conectada ao movimento ambientalista que emerge no mundo para discutir os processos de desenvolvimento para além do fator econômico (SACHS, 1986). Provocou, então, a necessidade de estruturação de um conjunto de leis que, entre 
outras atribuições, define as regras e uso de ocupação do solo, por meio de um zoneamento urbano espelhado nas ações que aconteciam no cenário nacional. Tais ações culminam na criação da Zona Especial de Preservação Histórica (ZEPH), em 1990, definindo espaços de preservação no centro histórico (NATAL, 1990); na Zona Especial Portuária (ZEP), em 1992, com definições claras de uso e ocupação do solo segundo as subzonas definidas - predominância residencial, institucional e de comércio e serviços (NATAL, 1992). O Plano Diretor de 1994 também foi outro documento legal que definiu áreas especiais, apresentando o bairro da Cidade Alta e Ribeira com valores histórico-culturais significativos que carecem de recuperação e revitalização, sendo o turismo um vetor dessa dinamização (NATAL, 1994).

Assim, o centro histórico de Natal vivenciou um processo de apogeu econômico e urbanístico que rapidamente refletiu em seu declínio, observado a partir das desocupações e abandono de imóveis, provocando um conjunto de intervenções públicas. São exemplos dessas intervenções o Seminário Ribeira Velha de Guerra (1993), o Projeto Viva Ribeira (1995), o Projeto Fachadas da Rua Chile (1996), o Projeto Ribeira (2000), entre outras.

Neste cenário, na década de 1990, é instituído o Programa Monumenta, no ano de 1999, em âmbito nacional que teve como objetivo preservar as áreas de patrimônio, conscientizar a população e aperfeiçoar a gestão visando a sua conservação (IPHAN, 2009). Em Natal, suas ações focaram no corredor cultural, englobando os bairros de Cidade Alta e Ribeira. Dentre as ações realizadas, houve um esforço para a identificação destes patrimônios utilizando inventários, bem como materiais de divulgação para a população (MORAIS, 2016).

Assim, embora as ações empreendidas pelas diversas políticas estaduais e federais estivessem como foco a valorização e reconhecimento do patrimônio, com incentivo à programação cultural, essas ações não solucionaram problemas estruturais em relação aos prédios e regiões abandonadas, principalmente de vazios urbanos, não alterando a dinâmica local. O que de fato ocorre é um movimento de preservação, evitando sua alteração física, sobretudo das fachadas dos prédios.

Do ponto de vista urbanístico, as estratégias de organização social da cidade são reforçadas pelo ideal do crescimento imobiliário que faz uso intenso do espaço e rapidamente o seu desuso, migrando para novas áreas. O medo, como objeto de consumo da cidade capitalista neoliberal, acompanha esse ritmo. São processos cada vez mais marcados pelo isolamento social e uso efêmero do espaço. De modo que a organização física do espaço urbano altera, sobretudo, a conjuntura social, por meio da forma de ver e se relacionar com o outro, da 
partilha, da dignidade humana e caminha para o processo de industrialização do medo, guiado por empresas especializadas (CALDEIRA, 2003).

No centro histórico, é imposta uma desordem social como fomento ao medo, refletida em estruturas de prédios abandonados, nas cores sombrias, nas fachadas e apesar de carregarem valor histórico, são distribuídos em pequenos espaços, com pouca arborização, confirmando o que preconiza a literatura sobre o aumento do medo do crime (CÁRDENAS O'BYRNE, 2017; FENNELL, 2017; JACOBS, 1961).

O terceiro momento do processo de desenvolvimento da cidade está inserido no contexto de abertura política e discussão da governança a partir da rede de atores locais, que ocorre no mundo (COUTINHO; NÓBREGA, 2019). Assim, as políticas de reabilitação urbana passam a incorporar a participação dos diversos atores e agentes que estão ali inseridos. O bairro da Ribeira se destacou particularmente com o Plano de Reabilitação de Áreas Centrais (PRAC-Ribeira) iniciado em 2005, a partir de uma equipe multidisciplinar sob os auspícios de um discurso de integração e de participação. Esse plano visa à reutilização de edifícios históricos fechados ou subutilizados por meio da habitação e outras funções urbanas, incluindo o turismo o que acabou por definir os limites do núcleo histórico de Natal.

O PRAC-Ribeira foi o primeiro documento que, além de definir os limites do núcleo histórico de Natal, elaborou um Plano de Valorização Turística Cultural da Ribeira, baseado na representatividade do turismo para o estado e manutenção da economia local. Estes foram construídos considerando o valor histórico, mas sobretudo em oficinas com atores locais buscando compreender o significado deste espaço para cada um destes grupos, em uma busca ideológica de participação popular concreta, que normalmente é pontual, fragmentada e pouco consciente (SEN, 2000).

Com a lógica da reabilitação e valorização do centro histórico de Natal, foi realizado o tombamento de alguns imóveis situados na região pelo Instituto do Patrimônio Histórico e Artístico (IPHAN, 2010) (Figura 1). Houve uma reforma do espaço físico a partir das políticas de incentivo ao tombamento do patrimônio, sem maior atenção para as características locais, incluindo aspectos das desigualdades sociais em comunidades marginalizadas, que poderiam ter maior participação nos processos decisórios (MELO, 2015).

Concomitantemente, na última década, foi instituída uma política nacional com foco nos centros históricos, denominada, em 2013, como PAC cidades históricas, em que a cidade do Natal foi contemplada com 10 projetos aprovados, de restauração, requalificação e reabilitação do centro histórico. 
Atualmente, apenas algumas obras de requalificação de praças foram finalizadas e as demais ainda se encontram em andamento, com previsão de entrega ao longo do primeiro semestre de 2021. Esta política tem como objetivo a valorização dos imóveis, em relação à estrutura física, e a capacitação de agentes visando a promoção patrimonial cultural das cidades históricas. Depreende-se, então, que apesar do forte apelo discursivo da participação e governança em rede de atores no processo de construção da política urbana, há que considerar o percurso histórico brasileiro e local marcado por estratégias de exclusão social, vulnerabilidade e desigualdade social. Assim, a participação permanece em ações pontuais, atuando como discurso sem efeitos práticos na dinâmica urbana e principalmente no ativismo social por meio de uma consciência coletiva (objetivo das políticas urbanas discutidas).

Figura 1 - Área tombada do centro histórico de Natal

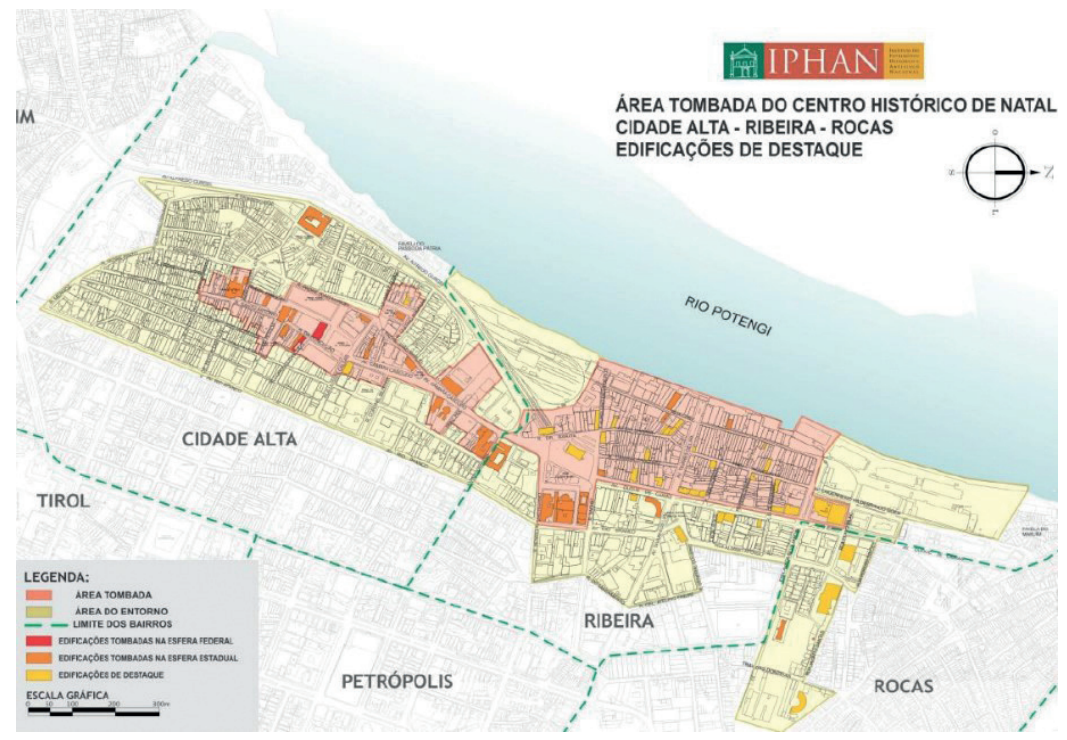

Fonte: IPHAN (2010).

Como resultado deste processo, as ruas - espaços de coletividade e convívio social - tornam-se abandonadas, utilizadas por pessoas que foram excluídas do círculo do consumo. Essas pessoas ficam à margem das decisões e do protagonismo social e são alvos de medidas de controle social, pelo seu comportamento concebido como 'desordenado', e o medo ganha espaço para atuar (KARAGIANNIS; MADJD-SADJADI, 2012; OH; REN; HE, 2019).

As estratégias continuam arraigadas em um forte apelo estético de embelezamento, por meio de prédios históricos com fachadas, cores, iluminação, 
utilizando o turismo como uma racionalidade, a partir da 'necessária' diversificação da oferta turística na cidade para além do sol e mar. As palavras de ordem comuns a todas as políticas urbanísticas implementadas neste período remetem a um processo de $r$-habilitação, re-qualificação, re-stauração que visam a valorização do patrimônio, mas não consideram as contradições existentes. Os "re's" impõem um consumo capitalista que passa também a empregar a dimensão econômica fortemente utilizada no turismo para a reestruturação de espaços públicos. Apesar disso, pichações, lixos e pouco uso do espaço público são aparentes.

De acordo com Jackson e Gouseti (2013) as relações estabelecidas no espaço revelam as percepções compartilhadas sobre o medo do crime. O espaço, apesar de estruturado fisicamente, não se torna local de encontro e partilha, provocando distanciamento entre o patrimônio e seu uso. O medo, neste momento, é percebido por um conjunto de ações que relaciona comportamentos desordenados de marginalizados e elementos urbanísticos que sinalizam abandono (pichações, lixo, ausência de manutenção) que se reforça pela alienação sobre o protagonismo social nas políticas públicas.

O quarto momento da política urbana no centro histórico é provocado por um conjunto de atores privados, que se configurou a partir do contexto neoliberal. Deve-se considerar que são bairros com características eminentemente comerciais e de serviços com algum uso institucional público. São comércios do tipo de rua que se contrapõem à lógica dos grandes espaços fortificados de consumo, como é o caso dos shoppings centers.

Essas características motivaram o levante do setor comercial local para direcionar políticas de revitalização do centro voltadas para usos mistos. Essas intervenções são visualizadas em arte de rua (especificamente o grafite), reformas de espaços culturais, melhoria na iluminação pública, instalação de lixeiras, reforço no patrulhamento por parte da Guarda Municipal e fomento às atividades culturais (principalmente a música). O conjunto destas intervenções são visualizadas na política denominada Novo Centro Histórico de Natal e reforçada por estratégias empresariarias que se unem em torno do coletivo denominado 'Viva o Centro'? De forma específica, a arte em mural utilizando o grafite em conjunto com as atividades culturais, principalmente as rodas de samba, impulsionaram uma dinâmica de encontros e partilhas em áreas específicas, doravante Beco da Lama e Espaço Ruy Pereira, ambos localizados no bairro da Cidade Alta.

Neste momento da história, a cidade do Natal sofre com o aumento de criminalidade urbana que atenta contra a vida, intensificada pelos meios midiáticos, que teve início com a crise do sistema penitenciário, em 2016. Todavia, quando

3 Uma associação de empresários e instituições locais que se unem para articular ações em torno da re-qualificação do bairro de Cidade Alta. 
contextualizada dentro da dinâmica da cidade, Cidade Alta (2,05\%) e Ribeira $(0,60 \%)$ não situam entre os bairros com maior incidência criminal entre os anos de 2011 a 2019 (Gráfico 1). Uma análise comparativa entre os Crimes Violentos Letais Intencionais (CVLI) e os Crimes Violentos ao Patrimônio (CVP) na Área Integrada de Segurança Pública número 2 (AISP 2) que compõe os bairros de Cidade Alta, Ribeira, Rocas e Santos Reis ${ }^{4}$ evidencia um aumento nas CVLI's no ano de 2016, ocasião em que eclode a crise (Gráfico 2). Ainda assim, sinaliza queda nos últimos anos, sendo hoje menor do que nos períodos anteriores à crise. As CVP's, por sua vez, apresentam contínua diminuição, sem interferência, com o contexto da crise no sistema penitenciário.

Estes dados nos fornecem direcionamentos para elucidar medo do crime como sentimento individualmente experimentado e socialmente compartido a partir da criação de estereótipos. É inversamente proporcional ao fenômeno da criminalidade e estimulado por empresas especializadas, no que se torna possível no contexto neoliberal. Assim, apesar de não existir dados que comprovem a real criminalidade urbana nestes bairros, inclusive em perspectiva histórica, há elementos simbólicos e físicos que fazem com que o medo adquira o controle do uso do espaço, fragmentando a experiência urbana. Esse fenômeno corrobora com a tese de que medo do crime e criminalidade não andam juntos (DORAN; BURGESS, 2012) e que as relações no contexto urbano e social contribuem para este entendimento.

Gráfico 1 - Crimes Violentos Letais Intencionais (CVLI) por bairros, Natal/RN (2011-2019)

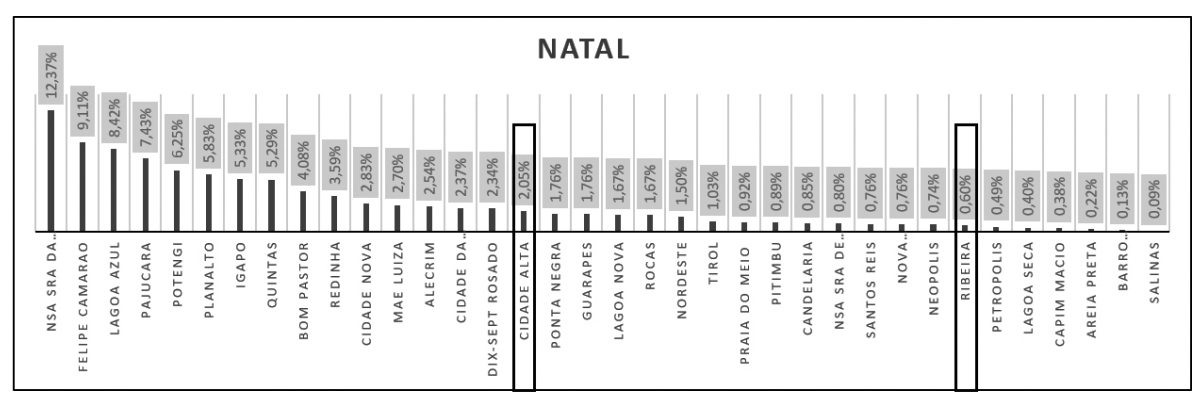

\section{Legenda \\ Bairros \\ Centro Histórico de Natal}

Fonte: Elaborado pelos autores a partir do Observatório da Violência do Rio Grande do Norte (2020a).

4 Rocas e Santos Reis são adjacentes ao centro histórico, inclusive palco do processo de segregação social no início do século XXI e, portanto, bairros vulneráveis e desiguais do ponto de vista social. 
Gráfico 2 - Condutas criminais na AISP 2 de Natal/RN - Comparativo CVP e CVLI (2013-2018)

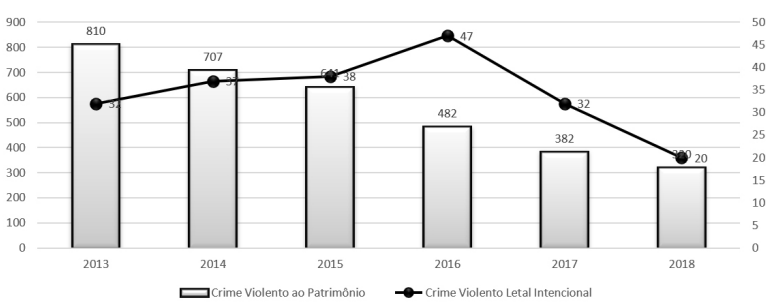

Fonte: Elaborado pelos autores a partir do Observatório da Violência do Rio Grande do Norte (2020b).

É importante pontuar que também há movimentos contra hegemônicos que ao longo dos anos lutam em busca da vivência harmônica entre os usuários do centro, e que têm na arte (principalmente a música) o seu ponto de encontro em praças, becos e largos. Morais (2016) caracteriza esse movimento como sendo silencioso, e que busca usos tradicionais dos espaços.

Entende-se, dessa forma, que a busca pelo bem-viver é balizada por recortes temporais, aliando a caminhos para melhores áreas de consumo e dotação de bens e serviços. Este caminhar acompanha as elites que se apropriam dos espaços para auferir lucros. A partir dessa dinâmica, compreende-se como se configura o espaço atual da cidade, que faz distinção de bairros que acomodam classes sociais diferentes e instalam um mecanismo de valorização do espaço, privilegiando a expansão do sentido centro-sul. Para fins de identificação visual, expõe-se na Figura 2, uma linha do tempo com os principais traços históricos concretizados no centro histórico de Natal a partir de um conjunto de intervenções públicas que modificaram a dinâmica urbana.

Figura 2 - Linha do tempo com as políticas de intervenção urbana no centro histórico de $\mathrm{Natal} / \mathrm{RN}$ e as narrativas

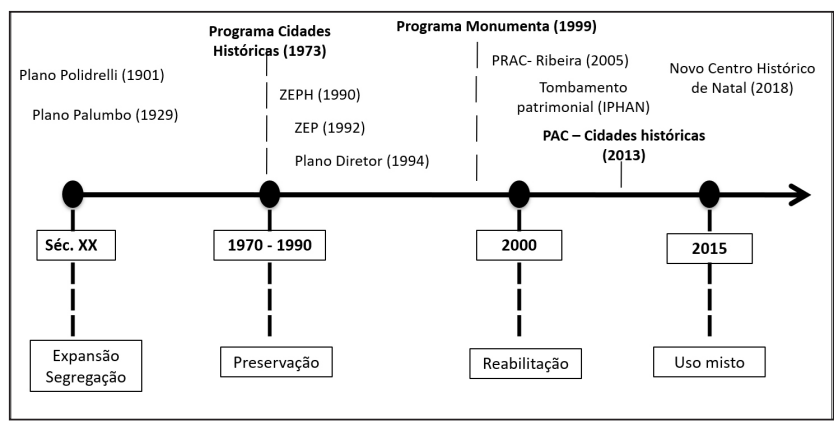

Fonte: Elaborada pelos autores com base nos dados da pesquisa, 2020. 
É importante pontuar que os bairros da Cidade Alta e Ribeira possuem uma malha urbana com poucas artérias principais, com forte presença de calçadas estreitas que finalizam em becos com alguns largos. Em relação à infraestrutura, os bairros do centro possuem boa infraestrutura de água, saneamento, drenagem, luz, telefonia, coleta regular de lixo, escolas, posto de saúde e linhas de transporte urbano que conecta com vários pontos da cidade. Na contramão, verifica-se deficiência de áreas verdes, que se limitam a algumas praças públicas e canteiros centrais das principais avenidas (NATAL, 2012). Essas características promovem um sentimento de medo, pela impossibilidade de as pessoas se sentarem e conviverem, falta de espaços de transição, bem como de falta de uma arborização adequada (DE BIASI, 2017).

Este conjunto de ações e iniciativas públicas analisadas reflete na forma, estrutura e conjuntura social do centro histórico de Natal, que abriga discussões sobre a sua manutenção e uso desses espaços que foram modificados em nome do processo de modernização. Assim, considerando as principais categorias do medo do crime apontada pela literatura, estruturou no Quadro 2 as categorias discutidas à luz da realidade do centro histórico de Natal/RN.

Quadro 2 - Medo do crime no centro histórico de Natal

\begin{tabular}{|c|c|}
\hline Dimensão & Centro Histórico de Natal \\
\hline $\begin{array}{c}\text { Organização } \\
\text { social }\end{array}$ & $\begin{array}{l}\text { Estratégias de único uso: do consumo - a partir de amplas atividades } \\
\text { (imobiliárias, comerciais, culturais, turística); } \\
\text { Crescimento imobiliário e reforço do desuso dos espaços migrando } \\
\text { para novas áreas com enclaves fortificados; } \\
\text { Desorganização social fomentada pelo abandono, pouco } \\
\text { arborização, cores opacas e lixo revestidos de pensamento } \\
\text { preservacionista; } \\
\text { Políticas de re-habilitação que utilizam da racionalidade econômica } \\
\text { do turismo e exclui os saberes e dinâmicas locais; } \\
\text { Ideologia da participação que não promove empoderamento social } \\
\text { ou escuta dos anseios locais por meio dos grupos tradicionais; }\end{array}$ \\
\hline Controle social & $\begin{array}{l}\text { Penalização de comportamentos desordenados por meio do } \\
\text { policiamento; } \\
\text { Controle do uso do espaço segregando-os socialmente para outras } \\
\text { áreas; } \\
\text { Capacidade de controle social por instituições formais } \\
\text { (policiamento) e informal (divisão social), no que gera um quadro } \\
\text { de medo com pouca ou nenhuma relação com a criminalidade. }\end{array}$ \\
\hline
\end{tabular}

Fonte: Elaborado pelos autores com base nos dados da pesquisa, 2020.

Depreende-se que apesar das intervenções urbanísticas carregarem diferentes recursos retóricos ao longo da história, revestidos da necessidade de 
expandir, de preservar, de reabilitar ou incentivar usos mistos, elas estão focadas na circulação de pessoas e o seu consumo. De forma específica, evidencia na dimensão da organização social (como estratégia para aumento do medo), uma atuação quase que invisível do estado através deste fomento econômico que perpassa pelo setor imobiliário, pelo comércio de rua, pela arte (como produto a ser consumido) e pelo turismo. No espaço físico, atua em um processo de desorganização social identificado pelo abandono, degradação, fachadas opacas, lixo e pouco espaço de transição e garantia de convívio através de arborização adequada. Ainda assim, pressionado pelo processo de globalização, o Estado incorpora no discurso das políticas urbanas estratégias de participação social pontual e ações preservacionistas que reforçam a ideia de desorganização, e fomentam a cidade neoliberal.

Cabe considerar que os ruídos sonoros, como música alta, barulho de tiro, gritaria, entre outros, não foram considerados pela pesquisa, como elementos do medo, conforme preconiza a literatura (TRINDADE; DURANTE, 2019). Porém, a arte exposta em murais foi percebida como característica física que diminui o sentimento do medo, sobretudo pela existência da música (arte) nestes locais, no que evidencia um quadro de encontros e partilhas sociais (HARVEY, 2014; JACKSON; GOUSETI, 2013; SAKIP; BAHALUDDIN; HASSAN, 2016).

$\mathrm{Na}$ dimensão de controle social para diminuição do medo do crime, a presença estatal não é oculta, e se formaliza por meio de instituições públicas, como a Polícia. A estratégia policial se apresenta de forma dicotômica: ora sinaliza o aumento do medo, ora a sua diminuição. O centro histórico de Natal/ $\mathrm{RN}$ carrega processos de desigualdade e vulnerabilidade social, assim a presença policial reforça este sistema que se conecta de forma direta com o aumento do medo (BAIERL, 2008). Cabe ainda considerar que a atuação policial possibilita a aquiescia da transgressão de uma sociabilidade violenta e, portanto, da capacidade física e simbólica de controle social (BOT'TERILL et al., 2013; SILVA, 2004).

De maneira geral, esse processo denota que o medo do crime não se manifesta de acordo com a criminalidade, e talvez por isso seja mais importante do que o crime e o comportamento dos criminosos, o que corrobora com as críticas à adoção acrítica de políticas norte-americanas de segurança pelos países latino-americanos (BLAUSTEIN, 2016; JONES; NEWBURN, 2019). A forma como a cidade está disposta através de suas características físicas e seus instrumentos de controle formal do estado possui mecanismos simbólicos que fazem do medo um objeto a ser consumido e retroalimentado. 


\section{CONSIDERAÇÕES FINAIS SOBRE O MEDO DO CRIME}

O processo de crescimento das nações vem sendo impulsionado pelo fenômeno da modernização neoliberal e da globalização modificando as estruturas e relações sociais. As cidades passam a ser lugar de consumo onde o medo tornase uma constante a ser percebida e manuseada. Apesar de não ser evidente, passase a sentir medo do outro (KORSTANJE, 2017), um medo simbólico, reforçado pelas relações de segregação social. Não é auferido pelo elemento externo como um campo de luta física, comumente medido pelos dados estatísticos criminais, mas principalmente pelas estruturas urbanas físicas a partir de uma leitura não verbal quando decide-se construir, modernizar, preservar, revitalizar e abandonar determinados espaços.

O turismo e o lazer, neste sentido, são racionalidades implementadas que fazem com que equipamentos sejam criados e/ou reformulados para seu uso. Essas medidas podem adquirir a conotação de um ordenamento social sob a prerrogativa de sua preservação e revitalização, e como medidas de controle social com direcionamento punitivo e restritivo, pensadas para um determinado espaço, principalmente dotado de elevada polarização social. Em ambos os aspectos, o turismo e lazer são vistos através de um valor meramente (ou simplesmente) econômico, esvaindo-se do seu papel como agente dinamizador na promoção de qualidade de vida. Não exclui o elemento econômico, mas se complementa no seu processo de desenvolvimento.

Esta pesquisa evidenciou as principais políticas de intervenção urbana executadas pelo setor público no centro histórico de Natal e as relacionou com a literatura sobre o medo do crime. Neste processo foi possível identificar quatro principais momentos históricos onde o medo do crime foi uma constante sob a prerrogativa de um ordenamento e controle social. De forma específica, o turismo é utilizado como racionalidade a partir do terceiro momento, em que coincide com justificativa de dinamização da oferta turística na capital. As políticas urbanas reforçam o ideal do medo a partir da sua ação e inação; do controle ou da desordem; da punição ou da exclusão nos equipamentos públicos e vias de ordenamento.

Sabe-se que as evidências desta pesquisa são um primeiro insumo para pensar o medo do crime no mundo pós-industrial a partir da estruturação do espaço físico, de forma específica, das políticas públicas de intervenção urbana. Entretanto, já aponta algumas importantes evidências discutidas neste trabalho, principalmente por incorporar uma dimensão diferente das pesquisas que visam o 
olhar do turista e o desenvolvimento econômico do turismo que não apresentam evidências sobre a realidade existente.

Para tanto, foram identificadas duas lacunas de pesquisa que podem impulsionar um aprofundamento e/ou novas abordagens de pesquisas. A primeira, refere-se a uma abordagem da vitimização relacionando com o perfil sociodemográfico do medo do crime na realidade investigada, de modo a entender como os diferentes perfis sociais percebem as estruturas urbanas. A segunda abordagem, remete a dimensão midiática do medo como disseminador de informações e construção de estereótipos, de forma específica a das mídias sociais.

\section{REFERÊNCIAS}

ADAM, I.; ADONGO, C. A. Do backpackers suffer crime? Empirical investigation of crime perpetrated against backpackers in Ghana. Journal of Hospitality and Tourism Management, [S. l.], v. 27, p. 60-67, 2016.

BAHIA, M.; FIGUEIREDO, S. O direito à cidade: reflexões sobre espaço público e lazer. In: AZEVÊDO, P. H.; BRAMANTE, A. C. (ed.). Gestão estratégica das experiências de lazer. Curitiba: Appris, 2017. p. 135-160.

BAIERL, L. F. Medo Social: dilemas cotidianos. Ponto-e-Vírgula: revista de Ciências Sociais, São Paulo, n. 3, p. 138-151, 2008.

BAUMAN, Z. Confiança e medo na cidade. São Paulo: Zahar, 2009.

BLAUSTEIN, J. Exporting criminological innovation abroad: discursive representation, 'evidence-based crime prevention' and the post-neoliberal development agenda in Latin America. Theoretical Criminology, [S. l.], v. 20, n. 2, p. 165-184, 2016.

BOTTERILL, D. et al. Violence, backpackers, security and critical realism. Annals of Tourism Research, [S. l.], v. 42, p. 311-333, 2013.

CALDEIRA, T. Enclaves fortificados: a nova segregação urbana. Novos Estudos Cebrap, São Paulo, n. 47, p. 155-176, 1997.

CALDEIRA, T. Cidade de muros: crime, segregação e cidadania. 34. ed. São Paulo: EDUSP, 2003.

CÁRDENAS O’BYRNE, S. Medir el uso del espacio público urbano seguro. Sociedad y Economía, [S. l.], n. 33, p. 33-54, 2017.

CASCUDO, L. História da cidade do Natal. 4. ed. Natal: RN Econômico, 2010. 
CASTELLS, M. A sociedade em rede. São Paulo: Paz e Terra, 1999.

CARLOS, A. A (re)produção do espaço urbano. São Paulo: EDUSP, 1994.

CERQUEIRA, D. Causas e consequências do crime no Brasil. Rio de Janeiro: BNDES, 2014.

CHAUHAN, V. Safety and security perceptions of tourists visitins Kashmir, India. Advances in Hospitality and Leisure, [S. l.], v. 3, n. 1, p. 3-17, 2015.

COSTA, A. T. M.; DURANTE, M. O. Police and fear of crime in distrito federal. Dados, [S. l.], v. 62, n. 1, p. 1-31, 2019.

COSTA, J. H.; HERRERA, M. R. G. Criminalidade, segurança pública e sustentabilidade em destinos turísticos. Marketing \& Tourism Review, Belo Horizonte, v. 4, n. 1, p. 1-39, 2019.

COSTA, J. H. et al. "Polícia do turista": contradições e revelações. International Journal of Safety and Security in Tourism/Hospitality, [S. l.], v. 18, p. 1-12, 2018.

COUTINHO, A. C. A.; NÓBREGA, W. R. M. Governance in tourist destinations: challenges in modern Society. Revista Brasileira de Pesquisa em Turismo, São Paulo, v. 13, n. 3, p. 55-70, 2019.

DE BIASI, A. Transforming vacant lots: investigating an alternative approach to reducing fear of crime. Journal of Environmental Psychology, [S. l.], v. 50, p. 125-137, 2017.

DORAN, B.; BURGESS, M. Putting fear of crime on the map: investigating perceptions of crime using geographic information systems. New York: Springer, 2012.

ENSLIN, et al. ProKnow-C, Knowledge Development ProcessConstructivist. Processo técnico com patente de registro pendente junto ao INPI. Brasil: Instituto Nacional de Propriedade Industrial - INPI, 2010.

FARRALL, S.; GRAY, E.; JACKSON, J. Theorising the fear of crime: the cultural and social significance of insecurities about crime. SSRN Electronic Journal, [S. l.], n. 5, p. 1-36, Jan. 2007.

FAZITO, M. Modernização turística: o papel do turismo no desenvolvimento. In: NÓBREGA, W.; FIGUEIREDO, S.; AZEVEDO, F. (org.). Perspectivas Contemporâneas de análise em turismo. Belém: NAEA, 2015. p. 108-126.

FENNELL, D. A. Towards a model of travel fear. Annals of Tourism Research, [S. l.], v. 66, p. 140-150, 2017.

FONSECA, M. A. P. Segunda residência, lazer e turismo. Natal: EDUFRN, 2012. 
GEORGE, R. Visitor perceptions of crime-safety and attitudes towards risk: the case of table Mountain National Park, Cape Town. Tourism \& Management, [S. l.], v. 31, n. 6, p. 806-815, 2010.

GIUSTI, G.; RAYA, J. M. The effect of crime perception and information format on tourists'willingness/intention to travel. Journal of Destination Marketing \& Management, [S. l.], n. 11, p. 1-7, 2019.

HALE, C. Fear of Crime: a review of the literature. International Review of Victimology, [S. l.], p. 1-77, 1996.

HARVEY, D. A justiça social e a cidade. São Paulo: Hucitec , 1980.

HARVEY, D. Cidades rebeldes: do direito à cidade à revolução urbana. São Paulo: Martins Fontes, 2014.

IPHAN, Instituto do Patrimônio Histórico e Artístico Nacional. Programa Monumenta: Recuperação de imóveis privados em centros históricos. Brasília: IPHAN, 2009.

IPHAN, Instituto do Patrimônio Histórico e Artístico Nacional. Cartilha informativa: tombamento do Centro Histórico de Natal. Natal: IPHAN, 2010.

JACKSON, J.; GOUSETI, I. Fear of crime. The Encyclopedia of Theoretical Criminology, [S. l.], n. 4, p. 1-6, 2013.

JACOBS, J. The death and life of America's cities. New York: Vintage Books, 1961.

JONES, T.; NEWBURN, T. Understanding transnational policy flows in security and justice. Journal of Law and Society, [S. l.], v. 46, n. S1, p. S12-S30, 2019.

JONES, T.; BLAUSTEIN, J.; NEWBURN, T. Researching cross-national policy mobilities in crime control. [S. l.: s. n.], 2019.

KARAGIANNIS, N.; MADJD-SADJADI, Z. Crime, criminal activity and tourism performance: Issues from the Caribbean. Worldwide Hospitality and Tourism Themes, [S. l.], v. 4, n. 1, p. 73-90, 2012.

KORSTANJE, M. The mobilities paradox: a critical analysis. Cheltenham, UK: Edward Elgar, 2017.

LEFEBVRE, H. Le droit à la ville. Paris: Anthropos, 1969.

LIMA, R.; COSTA, J. Avaliação de políticas públicas de turismo: aspectos metodológicos e os resultados da avaliação do PRODETUR em Parnamirim/ RN (2005-2012). Turismo em Análise, São Paulo, v. 26, n. 2, p. 451-474, 2015. MACHADO, M. B. T. Turismo, medo e violência. Turismo e Sociedade, Curitiba, v. 6, n. 1, p. 225-228, 2013. 
MACHADO, M. B. T. Factores restrictivos del turismo: la percepción de la demanda real y potencial sobre la seguridad pública en Rio de Janeiro (Brasil). Estudios y Perspectivas en Turismo, Buenos Aires, v. 27, p. 968-984, 2018.

MANSFELD, Y.; PIZAM, A. Tourism, security and safety: from theory to practice. London: British Library, 2006.

MELO, M. A. W. S. Turismo e patrimônio cultural: centro histórico de Natal/ RN. Natal: EDUFRN, 2015.

MORAIS, L. L. Turismo e patrimônio cultural: políticas, ações e intervenções no município de Natal/RN. Natal: EDUFRN, 2016.

NATAL. Lei $\mathbf{N}^{\circ}$ 3.942, de 09 de julho de 1990. Institui a Zona Especial de Preservação Histórica [...]. Natal: Prefeitura Municipal, [1990]. Disponível em: https://www.natal.rn.gov.br/semurb/paginas/File/InstrOrdSearch/31_Zona_ Especial_de_Preservacao_Historica-ZEPH.pdf. Acesso em: 18 set. 2020.

NATAL. Lei No 4.069, de 21 de maio de 1992. Regulamenta a Zona Especial Portuária [...]. Natal: Prefeitura Municipal, [1992]. Disponível em: http:// www.natal.rn.gov.br/semurb/paginas/File/Legislacao-novo\%20/32_Zona_ Especial_Portuaria-ZEP.pdf. Acesso em: 18 set. 2020.

NATAL. Lei complementar $\mathbf{N}^{\mathbf{0}} \mathbf{0 7}$, de 05 de agosto de 1994. Dispõe sobre o Plano Diretor de Natal [...]. Natal: Prefeitura Municipal, [1994]. Disponível em: http://medeirosadvogados.com/download/municipal/plano_diretor.pdf. Acesso em: 18 set. 2020.

NATAL. Conheça melhor o seu bairro. Natal: Semurb, 2012.

OBSERVATÓRIO DA VIOLÊNCIA DO RIO GRANDE DO NORTE. Condutas Violentas Letais Intencionais (2011-2019). Natal: Metabanco de Dados, 2020a.

OBSERVATÓRIO DA VIOLÊNCIA DO RIO GRANDE DO NORTE. Condutas Violentas Patrimoniais (2015-2019). Natal: Metabanco de Dados, 2020 b.

OH, G.; REN, L.; HE, P. Social disorder and residence-based fear of crime: The differential mediating effects of police effectiveness. Journal of Criminal Justice, [S. l.], v. 63, p. 1-11, 2019.

OZASCILAR, M.; MAWBY, R. I.; ZIYALAR, N. Perceptions of risk on vacation among visitors to Istanbul. Safer Communities, [S. l.], v. 18, n. 1, p. 16-29, 2019. 
PRECHATHAMWONG, W.; RUJIPRAK, V. Causal model of fear of crime among people in Bangkok. Kasetsart Journal of Social Sciences, [S. l.], Feb. 2018. RICHARDSON, R. Pesquisa social: métodos e técnicas. São Paulo: Atlas, 1999. ROO, Q.; CORTÉS, M. L. Inseguridad y turismo en Quintana Roo, México (1997-2013). Revista Criminalidad, v. 58, n. 1, p. 159-169, 2016.

SACHS, I. Estratégias de transição para o século XXI: desenvolvimento e meio ambiente. São Paulo: Studio Nobel, 1993.

SAKIP, S. R. M.; BAHALUDDIN, A.; HASSAN, K. The effect of mural on personal crime and fear of crime. Procedia - Social and Behavioral Sciences, [S. l.], v. 234, p. 407-415, Oct. 2016.

SEN, A. Desenvolvimento como liberdade. São Paulo: Companhia das Letras, 2000.

SILVA, A.; SOBRINHA, M.; CLEMENTINO, M. Novas tipologias habitacionais perante a expansão do capital imobiliário-turístico em Natal, RN. Cadernos Metrópole, São Paulo, v. 16, p. 141-162, 2006.

SILVA, B.; BEATO FILHO, C. Ecologia social do medo: avaliando a associação entre contexto de bairro e medo de crime. Revista Brasileira de Estudos de População, v. 30, p. 155-170, 2014.

SILVA, L. A. M. DA. Sociabilidade violenta: por uma interpretação da criminalidade contemporânea no Brasil urbano. Sociedade e Estado, Brasília, DF, v. 19, n. 1, p. 53-84, jun. 2004.

SOUZA, M. J. L. Mudar a cidade: uma introdução crítica ao planejamento e à gestão urbanos. Rio de Janeiro: Bertrand Brasil, 2002.

TINOCO, M.; BEZERRA, E.; TRIGUEIRO, F. Novos usos, novos fluxos. Complexidade e contradição na preservação arquitetural e reciclagem de edifícios no centro antigo de Natal. In: SEMINÁRIO PROJETAR, 3., 2007, Porto Alegre. Anais [...]. Porto Alegre: UFRGS-Projetar, 2007. p. 1-12.

TRINDADE, A.; DURANTE, M. Medo do crime e vitimização no Distrito Federal Analisando as vulnerabilidades de. DILEMAS: Revista de Estudos de Conflito e Controle Social, v. 12, n. 2, p. 239-265, 2019.

URRY, J. The tourist gaze. California: SAGE, 2002.

VILLAÇA, F. As ilusões do plano diretor. São Paulo: Edições do Autor, 2005. 